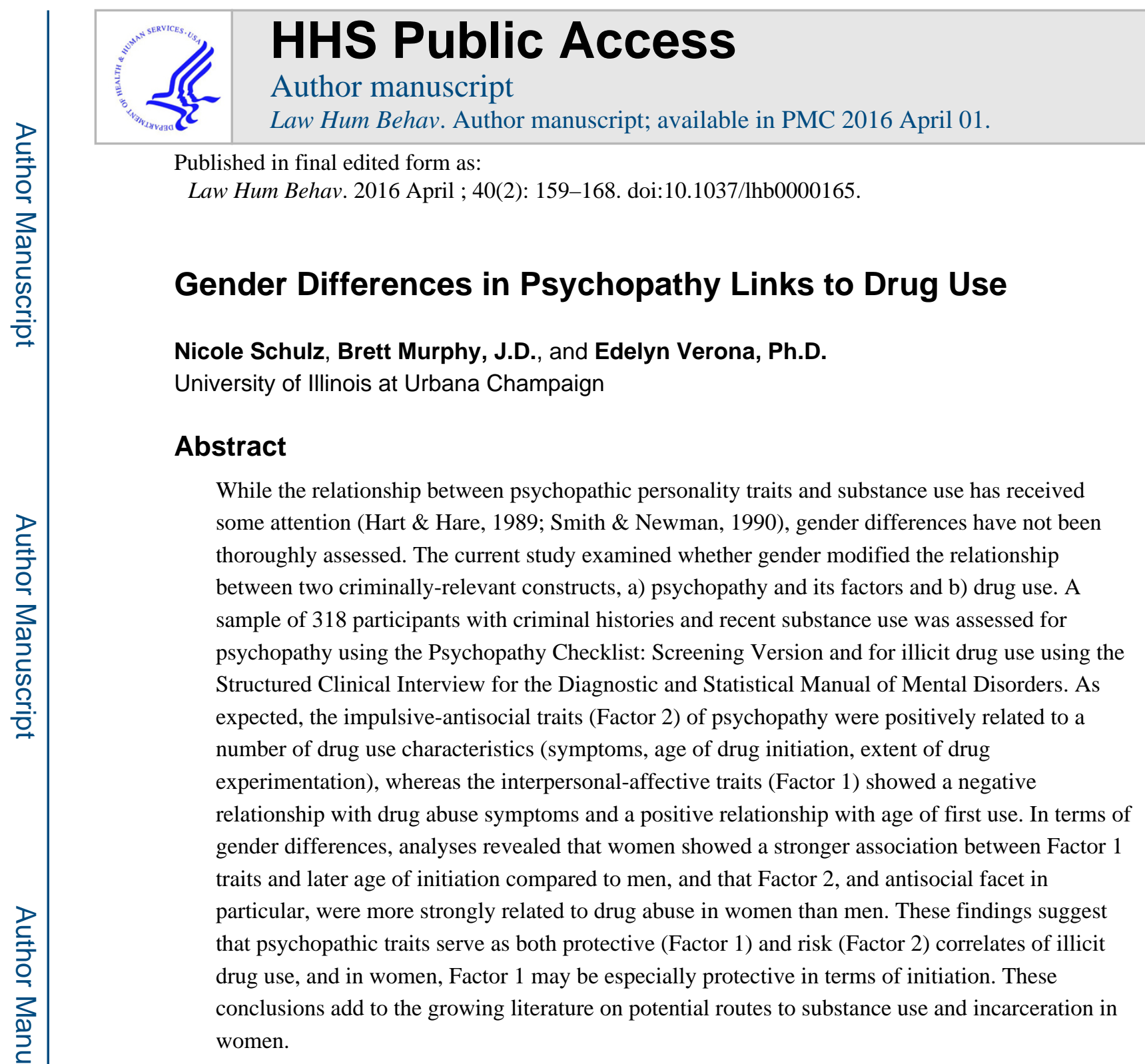

\title{
Keywords
}

Gender; Psychopathy; Drug Use

Substance use is strongly related to many other forms of criminal activity within the United States (Gordon, Kinlock, \& Battjes, 2004; Oser et al., 2011). Although male substance use has received more attention, female substance use appears to be rising, especially among younger cohorts (Keys, Grant, \& Hasin, 2008; Seedat et al., 2009). Moreover, illicit drug use may be an especially relevant pathway to incarceration in women relative to men (see Javdani, Sadeh, \& Verona, 2011, for a review; McClellan, Farabee, \& Crouch, 1997). For example, a sizably larger proportion of female state prison inmates are incarcerated for drug offenses, relative to males (Carson \& Sabol, 2012). Furthermore, the percentage of women arrested or incarcerated for drug offenses has risen substantially over time (Chesney-Lind \& Pasko, 2013; Mauer, Potler, \& Wolf, 1999). Because incarcerated women are more likely

Correspondence concerning this article should be addressed to Edelyn Verona, who is now at Department of Psychology, University of South Florida, 4202 E. Tampa, FL 33617, at everona@ usf.edu or 813-974-0392. 
than incarcerated men to be primary caregivers for their children (Glaze \& Maruschak, 2008), women's substance use and incarceration is especially likely to have negative effects on families and communities, making additional research on female criminality and substance use essential.

Psychopathic personality is an important criminally-relevant construct that has been linked to substance use (Kennealy, Hicks, \& Patrick, 2007; Smith \& Newman, 1990). The clinical construct of psychopathy encompasses a variety of characteristics, including serious empathy deficits, lack of remorse, impulsivity, and antisocial behavior, which can be characterized in terms of two related but distinguishable dimensions: interpersonal-affective traits and impulsive-antisocial traits (Hare, 2003). Although relationships between psychopathy and substance use have been evaluated within male samples (Walsh, Allen, \& Kosson, 2007; Smith \& Newman, 1990), and some female samples (Kennealy et al., 2007), research on gender differences in relationships between psychopathic traits and illicit drug use is sparse. This study aims to address this gap in the literature by exploring gender differences in the relationship between the two psychopathy factors (and distinct traits of psychopathy) and illicit drug use, utilizing a community-dwelling sample of participants with a history of substance use and involvement with the justice system.

\section{Gender and Substance Use}

There are strong theoretical and empirical grounds for examining potentially differential correlates of substance use in women and men. For example, a number of researchers have suggested that women are more likely to use substances to cope with negative emotions (McClellan et al., 1997; Chatham et al., 1999; though see Novak et al., 2003). Similarly, multiple studies have indicated that the association between trauma and substance use is greater in females than in males (Heffner, Blom, \& Anthenelli, 2011; Lipschitz, Grilo, Fehon, McGlashan, \& Southwick, 2000).

Research studies also suggest that gender may play a role in the temporal appearance of drug use. For example, adolescent males are more likely to be offered drugs (Moon, Hecht, Jackson, \& Spellers, 1999), and may initiate use of some substances at an earlier age than females (Shannon, Havens, Oser, Crosby, \& Leukefeld, 2011). Most of the research in this area, however, does not simultaneously include the full range of drug use behaviors (from drug initiation up to addiction) within the same study. Moreover, it is important to examine whether traits related to psychopathy are differentially related to different aspects of drug use (e.g., drug initiation, regular use, or substance use disorders) in women and men.

\section{Psychopathic Traits and Substance Use}

Psychopathic traits can be assessed with several distinct measurements; however, a popular group of instruments stem from Hare's Psychopathy Checklist (e.g., PCL-R, Hare, 1991, 2003; PCL:SV, Hart, Cox, \& Hare, 1995, 2003), which utilize in-depth interviews and observations to assess psychopathic traits. Mainly because of the impulsive-antisocial features of psychopathy, research has consistently shown evidence for a relationship between overall psychopathy scores and substance use behaviors, with persons with psychopathic traits more likely to exhibit serious substance use (Smith \& Newman, 1990; 
Hart \& Hare, 1989). Psychopathy has also been linked to a higher likelihood of polysubstance use (Smith \& Newman, 1990).

Research has also examined the two main factors of psychopathy. The interpersonalaffective traits (referred to as Factor 1) include deceitfulness, superficial charm, manipulativeness, deficient empathy, and lack of remorse (Hare, 2003). The impulsiveantisocial traits (referred to as Factor 2) are characterized by impulsivity, irresponsibility, weak behavioral control, and criminal versatility (Hare, 2003). Alternative three or four factor models split the original two factors into facets. The three facet model focuses on the interpersonal (e.g., deceit), affective (e.g., shallow affect), and lifestyle (e.g., impulsivity) facets (Cooke \& Michie, 2001). A fourth facet, the antisocial facet, is included in the fourfacet model, and assesses criminal involvement and versatility (Hare, 2003). Whether using a three-facet, four-facet or two-factor model, psychopathy factors show different relationships with a variety of constructs (e.g. Skeem, Miller, Mulvey, Tiemann \& Monahan, 2005).

Indeed, distinct relationships with drug use have been observed for the two main factors of psychopathy, which warrants their separate examination. Evidence suggests that serious substance use is most commonly associated with Factor 2 (impulsive-antisocial traits) and less so with Factor 1 (interpersonal-affective traits; Hart \& Hare, 1989; Smith \& Newman, 1990; Walsh et al., 2007). One study found that all three factors of Cooke and Michie's (2011) three-facet model were linked to an earlier age of substance abuse onset (Gustavson et al., 2007), although Campbell, Porter, and Santor (2004) did not find this kind of relationship. More research is needed in this area in order to obtain clarity about relationships between psychopathy traits and different indices of substance use. In addition, these studies have been primarily focused on men. Therefore, it is important to determine whether gender moderates relationships between psychopathy factors and several illicit drug use variables that range from drug initiation to disorder.

\section{Gender Framework}

An important consideration in the current psychopathy literature is whether psychopathic traits manifest similarly in women compared to men (Miller, Watts, \& Jones, 2011; Forouzan \& Cooke, 2005). For example, while the PCL-R is a good predictor of reoffending (recidivism) within male samples, psychopathy and recidivism are not as closely associated in women (Edens, Campbell, \& Weir, 2007). The theoretical perspective informing our examination of gender differences in psychopathy links to drug use rests on two considerations.

First, drug use appears to be a larger contributor to female incarceration rates (Carson \& Sabol, 2012; Chesney-Lind \& Pasko, 2013), which has implications for how both drug use and psychopathy are assessed in women relative to men. That is, to the extent that criminal and justice system involvement tends to increase an individual's psychopathy score, particularly on Factor 2, drug use may show a stronger association with psychopathic traits in women. If this is the case, and assuming that a label of psychopathy could have negative conceptual and legal implications, female drug users would be disproportionally affected 
since their psychopathy scores are more closely tied to their drug use. It is possible that the "War on Drugs" and other criminal justice policy approaches might affect psychological assessments of psychopathy in gendered ways, and, if so, research and practice in this field should be informed by this dynamic.

Second, psychopathic traits are generally more inconsistent with cultural gender norms for women than for men (Verona \& Vitale, in press). For instance, women are expected to be more nurturing, agreeable, and socially restrained, whereas men's promiscuous, aggressive, or risk-taking behaviors are more socially accepted. Women high on psychopathic traits would thus be considered especially deviant, relative to gender role expectations, compared to men (Verona \& Vitale, in press). This gendered difference in the social acceptability of psychopathic traits may lead to different risk levels for drug use in women versus men who are high in psychopathy. That is, since drug use is also more of a deviation from gender norms for women, it may be that drug use could relate more strongly to psychopathic traits in women.

Despite interesting theoretical considerations, there is limited research on psychopathy relations with substance use in women. One study conducted with incarcerated women showed significant relationships between Factor 2 traits and the use of a variety of substances (Kennealy et al., 2007), paralleling studies conducted on male samples described above. In contrast, Factor 1 traits showed a positive bivariate relationship with opiate use, but a negative relationship with total drug use in multivariate analyses (Kennealy et al., 2007).

A small number of studies have included both genders in reports of links between psychopathic traits and substance use. Consistent with the hypothesis above, Blonigen et al. (2005) found a slightly stronger relationship between drug dependence and personalityestimated scores on impulsive-antisocial traits (akin to Factor 2) in female than male participants, using a non-clinical sample. However, no significant relationships between Fearless Dominance (conceptually related to Factor 1) and illicit drug dependence were found for either gender.

Other studies have included both males and females, but have not statistically compared them. A study of youths, who were assessed using the PCL: Youth Version, Hemphala and Tengstrom (2010), found that the impulsive/irresponsible features of psychopathy, but not the arrogant/deceptive or the deficient affective features, related to drug use disorder symptoms similarly in both girls and boys. The same findings were found in a study of Dutch adolescents, assessed using an authorized translation of the Youth Psychopathy Traits Inventory (Das \& de Ruiter, 2003), with significant relationships between drug use disorder symptoms and grandiose-manipulative, callous-unemotional, and impulsive-irresponsible traits in both boys and girls (Hillege, Das, \& de Ruiter, 2010). Given the limitations of these studies (e.g., no direct comparisons between the genders, low base rates of illicit drug use), though, more research is needed. 


\section{Present Study}

There is a gap in the knowledge base concerning how gender may moderate the relationship between factors of psychopathy and substance use, especially when examining illicit drug use. In order to investigate illicit drug use reflecting the progression from initiation to addiction, we measured 4 drug use variables: retrospective reports of age of first drug initiation; range of drug experimentation; and clinically-rated symptoms of both drug abuse and drug dependence, as per the DSM-IV-TR (American Psychiatric Association, 2000).

We pursued three primary aims. First, we examined gender as a moderator of relationships between the two main factors of psychopathy and the drug use-related variables. Although we expected that Factor 2 traits would be associated with illicit drug use across both genders, we predicted that the relationship between drug abuse and dependence symptoms and Factor 2 traits would be stronger in women as per the reasons provided above (e.g., heightened link between drug use and incarceration in females compared to males; gender norm-deviance of psychopathy and substance use in women). Given that less research has associated Factor 1 traits with substance use in either gender, we did not have hypotheses about gender differences in that relationship.

Our second aim evaluated the role of Factor 1 traits, which distinguish psychopathy from general antisociality, in moderating the relationship between Factor 2 traits and drug use. Previous research indicates that Factor $1 \times$ Factor 2 interactions are associated with various disinhibited and dysregulated behaviors, such as borderline personality disorder (BPD) and self-harm behaviors, especially in women (Walsh \& Kosson, 2008; Verona, Sprague, \& Javdani, 2012; Sprague et al., 2012; but see Camp, Skeem, Barchard, Lilienfeld, \& Poythress, 2013). Thus, we expected higher drug use among women who had elevated levels of both Factor 1 and Factor 2 traits, given that substance use is also marked by difficulties in self-regulation and emotional coping in women (as noted above; McClellan et al., 1997).

Our third aim was to isolate what particular facets of psychopathy may account for relationships between psychopathy scores and drug use in women versus men. Although we primarily used the two factor model in main analyses, we conducted secondary analyses with the four facets of psychopathy and illicit drug use indicators, an analysis that has not been carried out before to our knowledge. In particular, we explored whether the antisocial facet, the scoring of which relies to some extent on criminal involvement, shows stronger relationships with drug use for either men or women.

\section{Method}

\section{Participants}

This study used a dataset drawn from a more extensive project studying relationships between illicit drug use, gender, and violence. The study involved 318 community-dwelling participants with recent histories of illicit drug use (past 6 months) and/or criminal justice involvement (past year), recruited by means of advertisements (28.6\%), flyers (24.8\%), counselor or substance use treatment centers (6.9\%), and other types of recruitment (e.g., word of mouth; $36.2 \%$ ). The majority of the participants had a history of legal involvement 
or court supervision, including $70.1 \%$ with histories of incarceration or parole/probation and $31.1 \%$ mandated to substance use treatment. Slightly less than half of the participants were women $(n=134,42.1 \%)$, and the participants ranged in age from 18 to 62 with a mean age of $34.75(\mathrm{SD}=11.954)$. Almost half of the participants indicated they were African American $(\mathrm{n}=153 ; 48.1 \%)$, followed closely by Caucasian $(\mathrm{n}=116 ; 36.5 \%)$. Most participants had completed at least some college courses $(56 \%, \mathrm{n}=178)$ or had a high school diploma or equivalent $(25.5 \%, \mathrm{n}=81)$, while $18.2 \%(\mathrm{n}=58)$ dropped out of or before high school. There were no significant gender differences in terms of age, ethnicity, recruitment source, or education. Due to missing data on some measures, the number of participants who were included in analyses varied from 311 to 318 .

\section{Procedures}

After signing an informed consent form approved by the IRB of record, participants engaged in a 3-hour interview. They received $\$ 35-40$ for participating (depending on whether they received a bonus for showing up to their first appointment). The interview consisted of a demographic portion, a life history interview for the Psychopathy Checklist: Screening Version (Hart, Cox \& Hare, 1995), modules from the Personality Disorder Interview (PDIIV; Widiger, Mangine, Corbitt, Ellis, \& Thomas, 1995), and modules from the Structured Clinical Interview for DSM-IV-TR Axis I Disorders (SCID-I; First, Spitzer, Gibbon, \& Williams, 2002). The interviews were conducted by trained staff, most of whom were doctoral students, supervised by a licensed Clinical Psychologist with substantial expertise in psychopathy and substance use disorders. Interviewers, who were well-versed in the literature on psychopathy, were trained by first observing and completing ratings of observed interviews, and then conducting interviews while supervised by trained interviewers.

\section{Measures}

Drug use variables-The SCID-I provided the information on different substance use indicators for this study. The drug use variables investigated in this paper were drug abuse symptoms, drug dependence symptoms, age of first drug initiation, and breadth of drug experimentation. We focused on all major drug categories (e.g., amphetamines, opiates, cannabis, cocaine, etc.), with the exclusion of alcohol, given our focus on illicit use. Age of drug use initiation was assessed as the earliest reported use of any illicit drug. One outlier was removed from this variable due to extreme scores (almost six standard deviations above the mean). Level of drug experimentation was operationalized as the extent to which participants reported using illicit drugs under each main drug category, according to a 3point scale incorporated in the SCID: $1=$ never used this drug or only used once, $2=$ used at least twice but less than 10 times, $3=$ used more than 10 times in one month. Numbers across drug categories were then summed to create an experimentation score.

Symptoms of substance abuse and dependence were identified using DSM-IV-TR criteria (APA, 2000). Drug abuse was identified by number of symptoms (out of 4 ) involving physically-dangerous use (i.e. driving under the influence), failure to fulfill responsibilities, and social or legal problems due to use. Drug dependence was indicated by number of symptoms (out of 6) involving tolerance, withdrawal, neglect of social obligations or 
activities, or lack of control over use. Although substance abuse and dependence symptoms are no longer distinguished in DSM-5 (APA, 2013), they are useful in representing use resulting in occupational/social difficulties (abuse) versus more serious, potentially physiological, addiction (dependence) (Hasin et al., 2003). Drug abuse and dependence symptoms were calculated as the number of symptoms participants endorsed experiencing at threshold levels for the self-identified drug of choice/most problematic drug.

Psychopathic traits-The Psychopathy Checklist: Screening Version (PCL-SV) is a 12 item rating scale useful for assessing psychopathy in participants residing in the community (Hart, Cox, \& Hare, 2003). Item ratings were based on a typical psychopathy life history interview about criminal, social, occupational, childhood family environment, and romantic histories. The interview responses regarding criminal behavior were corroborated with information attained from public criminal record reviews. The items were scored as $0=$ not present, $1=$ borderline present, and $2=$ present (Hart et al., 2003). Each of the items was classified into two factors: the interpersonal-affective or Factor 1 traits (e.g., deceitfulness, lack of empathy, superficial charm) and the impulsive-antisocial or Factor 2 traits (e.g., irresponsibility, impulsivity, lack of goals, or criminal versatility; Hart et al., 2003). The participants' item scores were then added separately for Factor 1 and Factor 2 traits. For the 4-facet model, Factor 1 was divided into the interpersonal facet (e.g., deceitful, superficial charm, grandiose) and the affective facet (e.g., lacks remorse and lacks empathy), with 3 items each. Factor 2 was split into the 3-item lifestyle (e.g., impulsive, lacks goals, and irresponsible) and antisocial facets (e.g., lacks behavioral controls, child antisocial behavior, adult criminality and versatility). Secondary raters were available for $57.5 \%$ of the interviews. Intra-class correlation coefficients indicated high inter-rater reliability for both Factor 1 (.95) and Factor 2 (.97).

While our participants were recruited from the community, there was a wide range of total psychopathy scores. Cutoff scores for the PCL:SV are typically conceptualized as $\geq 18$ indicating high scores, 13-17 middle, and $\leq 2$ as low (Hart et al., 2003). Within the current sample, $9.1 \%$ of participants scored within the high range ( $\geq 18), 25.7 \%$ in the middle range (13-17), and 65\% scored in the low psychopathy range ( $\leq 2)$. This range allowed us to use continuous factor scores in analyses.

Covariates-First, we included BPD symptoms to rule out the possibility that they might account for psychopathy-drug use relationships. BPD symptoms were assessed using the Personality Disorder Interview (PDI-IV; Widiger et al., 1995) and calculated as the number of DSM-IV symptoms which were coded as meeting threshold (out of 9 symptoms).

Because BPD was used in our primary analyses, one participant was not included in the dataset due to lack of BPD score.

Second, we adjusted for childhood environment that may influence drug use histories. We used several self-report measures to assess this construct. The Neighborhood Environment Scale (NES; Crum, Lillie-Blanton, \& Anthony, 1996) evaluated the participants' perceptions of the safety of their neighborhood growing up (Cronbach's alpha of .903), and the Childhood Trauma Questionnaire (CTQ; Bernstein et al., 2003) assessed reports of childhood maltreatment (sexual, physical, and neglect) (Cronbach's alpha of .92). Finally, 
the economic stability of the family of origin during childhood was assessed based on the occupation of primary caregivers, on a scale from 1-9 based on Hollingshead (1975) and the level of education of caregivers on a scale from 1-6 (from "dropped out before high school" to "education after a bachelor's degree"). Scores for socioeconomic status were reversed so that higher scores on all three of the childhood environment variables would indicate more negative childhood environments. These three measures (NES, CTQ, and reverse socioeconomic status) were standardized and then averaged into one combined variable which we used as a measure of childhood adversity.

\section{Data analysis}

For Aims 1 and 2, we conducted hierarchical multiple regression analyses on the four drug use variables in separate analyses. Within the first step of the analyses, we entered the covariates. We then entered mean-centered Factor 1 (F1) and Factor 2 (F2), and gender into step 2. Next, we entered interactions between the two factors and between each factor and gender in step 3. Finally, we entered F1 x F2 x Gender in step 4. Because certain demographic variables such as age and ethnicity were correlated with drug use, we included these variables as covariates within our analyses in addition to BPD and the childhood adversity composite discussed above. Aim 3 involved conducting post-hoc analyses using the four facets of psychopathy. We conducted a series of regressions that included all 4 facets as predictors of each of the drug use indicators, separately in each gender. Z transformations based on equations from Paternoster et al. (1998) were used to compare the betas between men and women.

We report effect sizes using squared semi-partial correlations (see Tables 1 and 2) and interpreted them according to Cohen, 1992's guidelines for squared partial correlations (with small effect sizes $=.02$, medium $=.15$, and large effects $=.35$ ).

\section{Results}

Our first research question explored whether gender modified relationships between the two psychopathy factors and drug use variables. Our regression model accounted for 13\% (age of initiation) to $31 \%$ (experimentation) of the variance in the drug use variables, indicating about medium effect sizes (see Tables 1 and 2 for parameter estimates for all models).

\section{Gender, Psychopathic Traits, and Drug Use Symptoms}

First, we examined results for drug use disorder symptoms (see Table 1). Age was positively related to both drug abuse and dependence symptoms, with older adults, who have had more time to manifest symptoms, reporting more lifetime symptoms. Although BPD showed small associations with drug abuse and dependence symptoms at the bivariate level ( $\mathrm{r}$ 's $=$. 140 and .157 , p's $\leq .013$ ), it did not show a significant relationship to drug use symptoms in the multivariate regression model (see Table 1). There was also no main effect of gender.

In terms of psychopathy factors, F1 showed a small negative relationship with drug abuse (B $=-.115, t=-2.372, p=.018$, CI $[-.211,-.020]$, squared semipartial $=.015)$ and no relationship to drug dependence, whereas $\mathrm{F} 2$ was positively related to both drug abuse $(\mathrm{B}=$. $237, t=4.566, p<.001, \mathrm{CI}[.135, .339]$, squared semipartial $=.054)$ and dependence $(\mathrm{B}=$. 
$338, t=3.690, p<.001, \mathrm{CI}[.158, .518]$, squared semipartial $=.035)$ at small effect sizes. A Gender x F2 interaction for drug abuse was marginally significant ( $\mathrm{B}=-.117, t=-1.903, p$ $=.058, \mathrm{CI}[-.239, .004]$, squared semipartial $=.009)$. Given a priori hypotheses about gender, we conducted follow up analyses showing that women displayed a stronger relationship between $\mathrm{F} 2$ and drug abuse $(\mathrm{B}=.235, t=4.572, p<.001$, CI[.133, .337], squared semipartial $=.110)$, a medium effect, compared to men's small-sized effect $(\mathrm{B}=.118, t=$ $2.695, p=.008, \mathrm{CI}[.032, .204]$, squared semipartial $=.037)$. Gender did not modify the relationship between $\mathrm{F} 2$ and drug dependence nor did it modify any relationships between F1 and drug abuse or dependence.

As stated earlier, women may be more likely to encounter substance-related legal troubles, which could inflate psychopathy scores (especially Factor 2 trait ratings). To examine if this could be the case in our sample, we removed the "legal problems" criterion when calculating drug abuse symptoms and re-ran analyses. The main effects of F1 (B $=-.096, t=-2.283, p$ $=.023$, CI [-.178, -.013], squared semipartial $=.014)$ and $\mathrm{F} 2(\mathrm{~B}=.177, t=3.964, p<.001$, CI $[.089, .265]$, squared semipartial $=.042$ ) were still significant, with a small effect sizes. The F2 x Gender interaction became even weaker ( $\mathrm{B}=-.091, t=-1.712, p=.088$, CI [-. $196, .014]$, squared semipartial $=.008$ ). Within gender, relationships between F2 and drug abuse remained for women, $\mathrm{B}=.184, t=4.168, p<.001$, CI [.097, .272], squared semipartial $=.099$, and men, B $=.076, t=2.031, p=.044$, CI $[.002, .150]$, squared semipartial $=.021$, although both were slightly smaller. Thus, these latter results indicate that $\mathrm{F} 1$ and $\mathrm{F} 2$ relations to drug abuse are not solely due to overlap in legal consequences.

However, the Gender x F2 interaction did weaken further.

\section{Gender, Psychopathic Traits, and Other Drug Use Indicators}

Next, we investigated results for drug experimentation and age of drug use initiation. Childhood adversity was related to a younger age of first drug use. In contrast, age and ethnicity were related to drug experimentation (versatility of drug use), with older and Caucasian participants reporting a wider variety of drug use.

Psychopathy F1 showed a small positive relationship with age of drug initiation (i.e., a later age of initiation; $\mathrm{B}=.251, t=1.998, p=.047$, CI [.004, .498], squared semipartial $=.011$ ). In contrast, F2 demonstrated a significant negative relationship of small size with age of drug use initiation (i.e., an earlier age of initiation; $\mathrm{B}=-.506, t=-3.807, p<.001$, CI [-.767, - . 244], squared semipartial $=.041)$ and a small positive relationship with drug use experimentation $(\mathrm{B}=.319, t=2.467, p=.014$, CI $[.065, .574]$, squared semipartial $=.014)$.

As before, there were no gender main effects, but gender interacted with psychopathy factors in terms of drug use initiation. As shown in Table 2, a F1 x Gender interaction ( $\mathrm{B}=$ $-.345, t=-2.029, p=.043$, CI $[-.679,-.010]$, squared semipartial $=.012)^{1}$ indicated a

\footnotetext{
${ }^{1}$ When we included the outlier identified for the age of first drug use variable, the significance of each independent variable in our final model remained largely the same. The only $\mathrm{p}$-value which changed from significant to non-significant was Factor $1(\mathrm{~B}=.241, \mathrm{t}=$ $1.790, \mathrm{p}=.074, \mathrm{CI}[-.024, .506]$, semipartial $=.01)$. The results for the gender interactions were very similar compared to the analyses reported in the results section, and levels of significance did not change. The results for the $\mathrm{F} 1 \mathrm{x}$ Gender interaction with the outlier included are $\mathrm{B}=-.361, \mathrm{t}=-1.981, \mathrm{p}=.048, \mathrm{CI}[-.719,-.002]$, squared semi-partial $=.011$. The $\mathrm{F} 2 \mathrm{x}$ Gender interaction is $\mathrm{B}=.316, \mathrm{t}$ $=1.853, \mathrm{p}=.065$, CI $[-.020, .651]$, squared semi-partial $=.01$.
} 
significant positive relationship between $\mathrm{F} 1$ traits and later age of drug use initiation for women ( $\mathrm{B}=.235, t=2.021, p=.046$, CI [.005, .466], squared semipartial $=.026)$, but not men (B $=-.016, t=-.126, p=.900, \mathrm{CI}[-.267, .235]$, squared semipartial $=.000)$ (see Figure 1). In other words, in women, F1 traits related to a later age of first drug use, whereas this was not the case for men. A Gender x F2 interaction for age of initiation was marginally significant, $\mathrm{B}=.292, t=1.835, p=.068$, CI $[-.021, .605]$, squared semipartial $=.010$, showing that women displayed a stronger relationship between $\mathrm{F} 2$ and an earlier age of initiation ( $\mathrm{B}=-.525, t=-4.115, p<.001, \mathrm{CI}[-.778, .-.272]$, squared semipartial $=.106)$ compared to men (B $=-.243, t=-2.146, p=.033$, CI [-.467, -.020$]$, squared semipartial= . 024), medium versus small effect sizes, respectively. ${ }^{1}$

\section{F1 X F2 Interaction}

Our second aim was to expand on previous research and analyze F1 x F2 interactions when explaining variance in drug use, and also whether this interaction was moderated by gender. As shown in Tables 1 and 2, we did not observe a F1 x F2 interaction for any of the drug use variables $(p$ 's $>.1)$, nor any significant gender moderation of F1 x F2 (all $p$ 's > .6). These observations suggest that F1 and F2 traits are related to drug use disorder symptoms when evaluated individually, but do not interact with one another.

\section{Facets of Psychopathy}

As per our third aim, regression analyses were run with the 4 facets of psychopathy entered as simultaneous predictors of each drug use indicator separately for men and women.

Overall, the lifestyle facet showed unique relationships with the majority of drug use variables across both genders, as it was positively correlated with drug abuse, drug abuse without the legal criterion, drug dependence, and drug experimentation in both genders. In contrast, the antisocial behavior facet showed ubiquitous relationships with several of the drug use indicators in women (i.e., with drug abuse, drug abuse without the legal criterion, drug dependence, and age of initiation). Notably, the relationship between the antisocial facet and drug abuse without the legal criterion was substantially smaller than for the unaltered drug abuse variable (see Table 3). In contrast, men showed a significant relationship between the antisocial facet and age of initiation only, and practically no relationship with drug abuse. Finally, the Factor 1 facets of interpersonal and affective features did not show unique relationships with any of the drug use indicators when controlling for shared variance with the other facets.

When statistically comparing unstandardized betas between men and women (see Paternoster, et al., 1998), the relationship between the antisocial facet and the drug abuse variable, but not other variables, significantly differed across gender $(z=2.35, p<.05)$.

\section{Discussion}

Although prior research has provided important information about the traits and criminal behaviors associated with substance use, previous work has been limited in that gender differences have not been assessed and only certain drug use variables have been investigated at the same time. The current study is the first, to our knowledge, to show how 
gender moderates relationships between certain psychopathic traits and multiple indicators of drug use in a community-dwelling sample characterized by high rates of drug use and criminal behavior.

The main findings of this study contribute to the literature on female drug use by showing that women demonstrate some similar relationships compared to men between psychopathic traits and various drug use variables, and a few differences. The two main gender differences revealed in our analyses are: (1) the link between drug abuse and antisocial behavior facet in particular appears to be stronger in women than in men; and (2) the core interpersonal and affective traits of psychopathy appear to be a modest protective factor in women, in terms of delaying their first use of illicit substances. Both of these findings lend support to the idea that psychopathic traits may be relevant to life trajectories in men and women, such as in terms of drug use.

\section{Gender, impulsive-antisocial traits (F2), and drug use-related variables}

Consistent with previous literature, F2 traits were positively related with all drug use variables investigated in this study (Hart \& Hare, 1989; Smith \& Newman, 1990; Walsh et al., 2007). The unique variance in $F 2$ traits was related to more abuse and dependence symptoms, a younger of age of initiation into illicit drug use, and a wider range of drug experimentation. Secondary analyses showed that the unique variance in the lifestyle facet of F2 especially seemed to account for most of these relationships, particularly for drug abuse, drug dependence, and drug experimentation across both genders. The lifestyle facet includes traits involving impulsivity, lack of goals, and irresponsibility (Hare, 2003); therefore, it is not surprising that these traits would be moderately associated with drug use and is consistent with previous research with female prisoners (Kennealy et al., 2007).

In terms of gender, both men and women showed similarly high levels of drug abuse and dependence symptoms, most likely because we recruited persons with drug histories into the study. Our results were somewhat consistent with our prediction of gender differences, in that women demonstrated a marginally-stronger relationship between F2 traits and drug abuse symptoms. More prominently, gender differences were strongest for relationships between substance use variables and the unique variance in the antisocial behavior facet, which to some extent can reflect lifetime incarcerations. This finding may explain why the Gender x F2 interaction for substance use was only marginally-significant-it is the antisocial facet and not impulsive lifestyle facet that explains gender differences in relationships between F2 and drug use. Thus, our results indicate that the link between antisocial behavior and drug use is stronger in women than in men. This could either be a reflection of gender differences in underlying psychological characteristics of psychopathy, or it could be a reflection of gendered effects of current drug policy paradigms such as the "War on Drugs."

Based on theory and data from criminology and feminist psychology (Chesney-Lind \& Pasko, 2013; Javdani, Sadeh, \& Verona, 2011), we contend that the finding of a stronger relationship between F2-related antisocial ratings and drug abuse symptoms in women may be a reflection of the fact that current drug laws seem to play a disproportionate role in overall female incarceration rates (e.g., Mauer, Potler, \& Wolf, 1999). For instance, in 2010, 
$25 \%$ of females in state prison were incarcerated for drug offenses, as compared to $17 \%$ of males (Carson \& Sabol, 2012). Our results, thus, may reflect the idea that indexes of incarceration and criminally-involved life trajectories are more largely driven by drug use symptoms and addiction in women, which may indicate that PCL measurements of males and females differ based upon the realities of criminal justice policies, not only due to person-centered variables.

Consistent with this conceptualization, gender differences were not found between F2 antisocial traits and drug dependence symptoms. This contrast indicates that antisocial women are more likely to exhibit the legal and social problems indicated by drug abuse symptoms but not necessarily be at higher risk for transitioning into more serious addiction. As mentioned previously, involvement in the legal system due to drug use could be accounting for the heightened relationship between F2 and drug abuse in women. To the extent that drug dependence does not reflect these legal problems, within our conceptualization it makes sense that gender did not moderate relationships between F2 traits and drug dependence. Indeed, removing the legal criterion from the drug abuse variable substantially reduced the relationship between drug abuse and the antisocial facet in women. This was not the case for the lifestyle facet, which showed similar relationships with drug abuse whether or not the legal criterion was included. Future research may consider whether drug-related social and occupational dysfunction more generally (not just legal problems) are also reflected in ratings of psychopathy F2 traits more so in women than men.

\section{Gender, interpersonal-affective traits (F1), and drug use}

This study included primary interpersonal/affective psychopathic traits (F1), such as interpersonal charm and manipulation, shallow emotions and lack of empathy, that differentiate psychopathy from general antisociality, and thus may further explain drug use behaviors in a range of antisocial populations. The current study found that F1 traits were associated with fewer drug abuse symptoms with a small effect size (squared semipartial= . 014). This finding is consistent with other work showing that the unique variance of F1 tends to be only modestly associated with drug use outcomes, and, when it is related, may be protective of these drug use behaviors (Hare \& Hart, 1989; Kennealy et al., 2007; Smith \& Newman, 1990).

Importantly, gender served as a moderator of the relationship between F1 and age of drug use initiation. Specifically, F1 traits were associated, albeit at a small effect size, with a later age of first drug use in women compared to men. This finding demonstrates that psychopathic traits in general, and its different features, and not only general antisociality (captured by F2), are important for understanding gender-differentiated manifestations of drug use, most notably in terms of early drug initiation. Further, these findings are partly consistent with Kennealy et al.'s (2007) study of female prisoners, which found a negative relationship between F1 traits and total drug use in women.

One explanation for the fact that women's age of drug use initiation was more affected than men's by F1 (and to a lesser extent F2) traits involves the idea that psychopathic traits are gender role-inconsistent for women. For example, males in general may initiate the use of 
certain substances at younger ages (Shannon et al., 2011), and engaging in substance using behavior may be more socially acceptable or even encouraged among male children within society (Griffin, Scheier, Botvin, \& Diaz, 2000; see Gomberg, 1982). Therefore, initiation of drug use in girls may be more impacted by psychopathic personality traits in women.

Women higher on F2 were marginally more likely than men higher on F2 to initiate drug use at a younger age. More prominently, F1 was protective of earlier initiation into drug use in women more than men. Young women high on F1 traits, such as having a colder, less nurturing personality, may be less attached to peer groups, and thus less vulnerable to peer pressure involving drug-taking activities (such as having parties where drugs and alcohol are present). Indeed, the fact that this relationship was only found for age of drug initiation, not for lifetime drug abuse and dependence symptoms, may indicate that F1 traits play a larger role in terms of initiating drug use, but become less important as individuals turn to more serious drug use. Interestingly, when looking at the facet level, neither interpersonal nor affective facets showed a unique relationship with age of drug initiation, though the relationships were in the expected direction for women.

Finally, expectations regarding our second main goal of the study involving the moderating role of F1 in relationships between F2 and drug use in women were not supported. We based this hypothesis mostly on research findings that a F1 x F2 interaction was associated with behavioral dysregulation in women (e.g., Sprague et al., 2012). Instead, the current study's findings suggest that paths to substance use implicated by psychopathic traits do not overlap with those related to emotionally-dysregulated behaviors like BPD or self-harm risk in women.

\section{Strengths and Limitations}

As with any study, this study has both strengths and limitations. Some limitations inevitably reside within the methods of the study. For example, the measures of substance use and personality traits rely moderately on reports of past behavior. It is possible that participants may not be able to objectively report their behaviors or may inaccurately report behaviors due to social desirability factors or factors confounding personality and retrospective reports. Furthermore, the study also cannot decipher the temporal order underlying relationships between psychopathic traits and drug use behaviors; thus, we tried to provide various explanations for the associations observed. Longitudinal work is necessary to inform hypotheses about putative etiological factors linking psychopathy and drug use.

A major advantage of this study's design was that most participants were pulled from communities that were more likely to have substance use problems and a history of legal involvement. This allowed us to study elevated rates of both drug use and also personality traits such as psychopathy, but among a group of individuals who were not incarcerated long-term (and thus making the findings potentially more generalizable). In addition, our sample was relatively well balanced between males and females, allowing us greater ability to explore potential gender differences, which is unique to this literature. Finally, the breadth and depth provided by our extensive interview procedure allowed us an enhanced ability to effectively analyze relationships without over relying on common method variance (e.g., 
review of criminal records and ratings based on clinician impressions in addition to selfreport).

\section{Future Directions and Clinical/Legal Implications}

The current study is the first to directly study gender differences between the factors and facets of psychopathy assessed using the PCL: SV and multiple illicit drug use variables. The outcomes of this study not only add to the growing field of female drug use but can also inform future hypotheses regarding gendered pathways to drug use. For instance, drug use may be more tightly linked to history of criminal involvement in women than men. Beyond elucidating gender-specific links between antisociality and drug use, our findings have several conceptual and legal implications for the construct and measurement of psychopathy in women. First, Psychopathy Checklist scores in women may be more heavily linked to incarceration policies of the nation's "war on drugs." Given that F2 scores elevate total psychopathy scores, bringing persons closer to potential cut-offs used in clinical or legal agencies, the possibility that a drug use history would confound interpretation of psychopathy scores or labels more so in women than men should be considered in making policy or legal decisions.

Second, the fact that F1 traits were shown to have a stronger protective relationship with early drug use for women than men indicates that the interpersonal-affective traits are also important to consider in understanding drug use trajectories in women. Importantly, the fact that F1 traits did not interact with F2 to explain drug use in this study, whereas it has been shown to do so when it comes to BPD and self-harm, suggests that F1 traits may show complex relationships with other forms of disorder in women. This would indicate that researchers should pursue more systematic examinations of the nomological network of F1 traits and their measurement in women. Overall, these findings could inform further research aiming to improve criminal justice policy and treatment strategies for men and women.

\section{Acknowledgments}

This research was supported by National Institute of Drug Abuse grant \# 1R21DA027140.

Special thanks to Konrad Bresin, Michael Perino, and Micheal Kruepke. Additional thanks to Justin Rhodes, and Petra Majdak for their comments on earlier drafts of this paper.

This research was supported by National Institute of Drug Abuse.

\section{References}

American Psychiatric Association. Diagnostic and statistical manual of mental disorders. 4. 2000. text rev

American Psychiatric Association. Diagnostic and statistical manual of mental disorders. 5. Arlington VA: American Psychiatric Publishing; 2013.

Bernstein DP, Stein JA, Newcomb MD, Walker E, Pogge D, Ahluvalia T, Zule W. Development and validation of a brief screening version of the Childhood Trauma Questionnaire. Child Abuse \& Neglect. 2003; 27(2):169-190. [PubMed: 12615092]

Blonigen DM, Hicks BM, Krueger RF, Patrick CJ, Iacono WG. Psychopathic personality traits: Heritability and genetic overlap with internalizing and externalizing psychopathology. Psychological medicine. 2005; 35(5):637-648. [PubMed: 15918340] 
Camp JP, Skeem JL, Barchard K, Lilienfeld SO, Poythress NG. Psychopathic Predators? Getting Specific about the Relation between Psychopathy and Violence. Journal of Consulting and Clinical Psychology. 2013; 81(3):467-480. [PubMed: 23316742]

Campbell MA, Porter S, Santor D. Psychopathic traits in adolescent offenders: an evaluation of criminal history, clinical, and psychosocial correlates. Behavioral Sciences \& The Law. 2004; 22(1):23-47. [PubMed: 14963879]

Carson, EA.; Sabol, WJ. Prisoners in 2011. Washington, DC: US Department of Justice, Bureau of Justice Statistics; 2012. NCJ 239808

Chatham LR, Hiller ML, Rowan-Szal GA, Joe GW, Simpson DD. Gender differences at admission and follow-up in a sample of methadone maintenance clients. Substance use and Misuse. 1999; 34(8):1137-1165. [PubMed: 10359226]

Chesney-Lind, M.; Pasko, L. The Female Offender: Girls, women and crime. 3. Los Angeles, CA: Sage Publications; 2013.

Cohen J. A power primer. Psychological bulletin. 1992; 112(1):155. [PubMed: 19565683]

Crum RM, Lillie-Blanton M, Anthony JC. Neighborhood environment and opportunity to use cocaine and other drugs in late childhood and early adolescence. Drug and Alcohol Dependence. 1996; 43(3):155-161. [PubMed: 9023071]

Das, J.; de Ruiter, C. Youth Psychopathic traits Inventory: Geautoriseerde Nederlandse vertaling. (Youth Psychopathic traits Inventory; Authorized Dutch translation). 2003. Unpublished research version

Edens JF, Campbell JS, Weir JM. Youth psychopathy and criminal recidivism: a meta-analysis of the psychopathy checklist measures. Law and human behavior. 2007; 31(1):53. [PubMed: 17019617]

Feske F, Tarter RE, Kirisci K, Pilkonis PA. Borderline personality and substance use in women. The American Journal on Addictions. 2006; 15(2):131-137. [PubMed: 16595350]

First, MB.; Spitzer, RL.; Williams, JBW.; Gibbon, M. Structured clinical interview for DSM-IV-TR (SCID-I)-research version. New York, NY: Biometrics Research, New York State Psychiatric Institute; 2002.

Forouzan E, Cooke DJ. Figuring out la femme fatale: conceptual and assessment issues concerning psychopathy in females. Behav Sci Law. 2005; 23(6):765-778.10.1002/bsl.669 [PubMed: 16333807]

Glaze, L.; Maruschak, M. Parents in prison and their minor children. Washington: Bureau of Justice Statistics; 2008.

Gomberg ESL. Historical and political perspective: Women and drug use. Journal of Social Issues. 1982; 38(2):9-23.

Gordon MS, Kinlock TW, Battjes RJ. Correlates of early substance use and crime among adolescents entering outpatient substance abuse treatment. American Journal of Drug and Alcohol Abuse. 2004; 30(1):39-59. [PubMed: 15083553]

Griffin KW, Scheier LM, Botvin GJ, Diaz T. Ethnic and gender differences in psychosocial risk, protection, and adolescent alcohol use. Prevention Science. 2000; 1(4):199-212. [PubMed: 11523748]

Gustavson C, Ståhlberg O, Sjödin AK, Forsman A, Nilsson T, Anckarsäter H. Age at onset of substance abuse: a crucial covariate of psychopathic traits and aggression in adult offenders. Psychiatry research. 2007; 153(2):195-198. [PubMed: 17659353]

Hare, RD. Manual for the hare psychopathy checklist. 2. Toronto, Ontario, Canada: Multi-Health Systems; 2003. revised

Hare, RD. Manual for the revised psychopathy checklist. 1. Toronto, Ontario, Canada: Multi-Health Systems; 1991.

Hart, SD.; Cox, DN.; Hare, RD. Manual for the psychopathy checklist: Screening version. Toronto: Multi-Health Systems; 1995.

Hart, SD.; Cox, DN.; Hare, RD. Manual for the psychopathy checklist: Screening version. Toronto: Multi-Health Systems; 2003.

Hart SD, Hare RD. Discriminant validity of the psychopathy checklist in a forensic psychiatric population. Psychological Assessment: A Journal of Consulting and Clinical Psychology. 1989; 1(3):211-218. 
Hasin DS, Schuckit MA, Martin CS, Grant BF, Bucholz KK, Helzer JE. The Validity of DSM-IV Alcohol Dependence: What Do We Know and What Do We Need to Know? Alcoholism: Clinical and Experimental Research. 2003; 27(2):244-252.

Heffner JL, Blom TJ, Anthenelli RM. Gender differences in trauma history and symptoms as predictors of relapse to alcohol and drug use. American Journal on Addictions. 2011; 20(4):307311. [PubMed: 21679261]

Hemphala M, Tengström A. Associations between psychopathic traits and mental disorders among adolescents with substance use problems. British Journal of Clinical Psychology. 2010; 49(1):109_ 122. [PubMed: 19457274]

Hillege S, Das J, de Ruiter C. The Youth Psychopathic Traits Inventory: Psychometric Properties and Its Relation to Substance Use and Interpersonal Style in a Dutch Sample of Non-Referred Adolescents. Journal Of Adolescence. 2010; 33(1):83-91. [PubMed: 19559475]

Hollingshead, AB. Four factor index of social status. 1975. Unpublished manuscript

Javdani S, Sadeh N, Verona E. Gendered social forces: A review of the impact of institutionalized factors on women and girls' criminal justice trajectories. Psychology, Public Policy, and Law. 2011; 17(2):161.

Kennealy PJ, Hicks BM, Patrick CJ. Validity of factors of the psychopathy checklist-revised in female prisoners: Discriminant relations with antisocial behavior, substance abuse, and personality. Assessment. 2007; 14(4):323-340. [PubMed: 17986651]

Keyes KM, Grant BF, Hasin DS. Evidence for a closing gender gap in alcohol use, abuse, and dependence in the United States population. Drug and Alcohol Dependence. 2008; 93(1-2):21-29. [PubMed: 17980512]

Lipschitz DS, Grilo CM, Fehon D, McGlashan TM, Southwick SM. Gender differences in the associations between posttraumatic stress symptoms and problematic substance use in psychiatric inpatient adolescents. The Journal of nervous and mental disease. 2000; 188(6):349-356. [PubMed: 10890343]

Mauer, M.; Potler, C.; Wolf, R. Gender and Justice: Women, drugs, and sentencing policy. Washington, DC: Sentencing Project; 1999.

McClellan DS, Farabee D, Crouch BM. Early victimization, drug use, and criminality. Criminal Justice \& Behavior. 1997; 24(4):455-476.

Miller JD, Watts A, Jones SE. Does psychopathy manifest divergent relations with components of its nomological network depending on gender? Personality and Individual Differences. 2011; 50(5): 564-569.

Moon DG, Hecht ML, Jackson KM, Spellers RE. Ethnic and gender differences and similarities in adolescent drug use and refusals of drug offers. Substance Use \& Misuse. 1999; 34(8):1059-1083. [PubMed: 10359222]

Novak A, Burgess ES, Clark M, Zvolensky MJ, Brown RA. Anxiety sensitivity, self-reported motives for alcohol and nicotine use and level of consumption. Journal of Anxiety Disorders. 2003; 17(2): 165-180. [PubMed: 12614660]

Oser C, Leukefeld C, Staton-Tindall M, Duvall J, Garrity T, Stoops W, Booth B. Criminality among rural stimulant users in the United States. Crime \& Delinquency. 2011; 57(4):600-621. [PubMed: 21686091]

Paternoster R, Brame R, Mazerolle P, Piquero A. Using the correct statistical test for the equality of regression coefficients. Criminology. 1998; 36(4):859-866.

Patrick CJ, Bradley MM, Lang PJ. Emotion in the criminal psychopath: startle reflex modulation. Journal of abnormal psychology. 1993; 102(1):82. [PubMed: 8436703]

Sansone RA, Sansone LA. Substance use disorders and borderline personality: common bedfellows. Innovations in clinical neuroscience. 2011; 8(9):10.

Seedat S, Scott K, Angermeyer MC, Berglund P, Bromet EJ, Brugha TS, Demyttenaere K, de Girolamo G, Haro JM, Jin R, Karam EG, Kovess-Masfety V, Levinson D, Medina Mora ME, Ono Y, Ormel J, Pennell BE, Posada-Villa J, Sampson NA, Williams D, Kessler RC. Cross-national associations between gender and mental disorders in the world health organization world mental health surveys. Arch Gen Psychiatry. 2009; 66(7):785-795. [PubMed: 19581570] 
Serras A, Saules KK, Cranford JA, Eisenberg D. Self-injury, substance use, and associated risk factors in a multi-campus probability sample of college students. Psychology of addictive behaviors. 2010; 24(1):119. [PubMed: 20307119]

Shannon LM, Havens JR, Oser C, Crosby R, Leukefeld C. Examining gender differences in substance use and age of first use among rural Appalachian drug users in Kentucky. American Journal of Drug and Alcohol Abuse. 2011; 37(2):98-104. [PubMed: 21142705]

Skeem JL, Miller JD, Mulvey EP, Tiemann J, Monahan J. Using a five-factor lens to explore the relation between personality traits and violence in psychiatric patients. Journal of Consulting and Clinical Psychology. 2005; 73:454-465. [PubMed: 15982143]

Smith SS, Newman JP. Alcohol and drug abuse-dependence disorders in psychopathic and nonpsychopathic criminal offenders. Journal of Abnormal Psychology. 1990; 99(4):430. [PubMed: 2266219]

Sprague J, Javdani S, Sadeh N, Newman J, Verona E. Borderline personality disorder as a female phenotypic expression of psychopathy? Personality Disorders: Theory, Research, and Treatment. 2012; 3(2):127-139.

Verona E, Patrick CJ, Joiner TE. Psychopathy, antisocial personality, and suicide risk. Journal of abnormal psychology. 2001; 110(3):462. [PubMed: 11502089]

Verona E, Sprague J, Javdani S. Gender and factor-level interactions in psychopathy: Implications for self-directed violence risk and borderline personality disorder symptoms. Personality Disorders: Theories, Research, and Treatments. 2012; 3(3)

Verona, E.; Vitale, J. Psychopathy in women: Assessment, manifestations, and etiology. In: Patrick, CJ., editor. Handbook of Psychopathy. 2. New York: Guilford; (in press)

Walsh, Allen; Kosson. Beyond social deviance: Substance use disorders and the dimensions of psychopathy. Journal of Personality Disorders. 2007; 21(3):273-288. [PubMed: 17536940]

Walsh Z, Kosson DS. Psychopathy and violence: The importance of factor level interactions. Psychological Assessment. 2008; 20(2):114-120. [PubMed: 18557688]

Walter M, Gunderson JG, Zanarini MC, Sanislow CA, Grilo CM, McGlashan TH, Morey LC, Yen S, Stout RL, Skodol AE. New onsets of substance use disorders in borderline personality disorder over 7 years of follow-ups: findings from the collaborative longitudinal personality disorders study. Addiction. 2009; 104(1):97-103. [PubMed: 19133893]

Widiger, TA.; Mangine, S.; Corbitt, EM.; Ellis, CG.; Thomas, GV. Professional manual. Psychological Assessment Resources; Odessa, FL: 1995. Personality Disorder Interview-IV. A semi-structured interview for the assessment of personality disorders.

Law Hum Behav. Author manuscript; available in PMC 2016 April 01. 


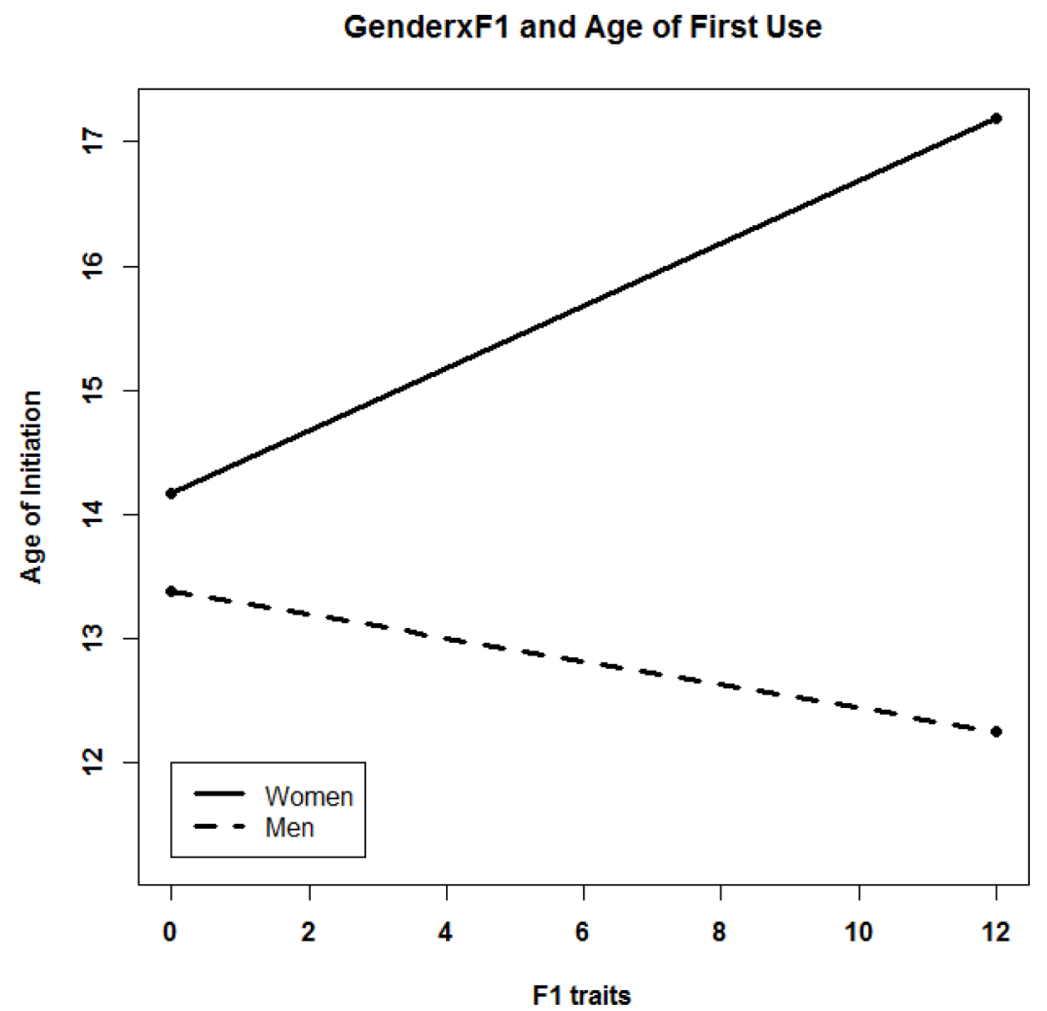

Figure 1.

Relationship between Factor 1 psychopathy traits and age of reported drug initiation. 

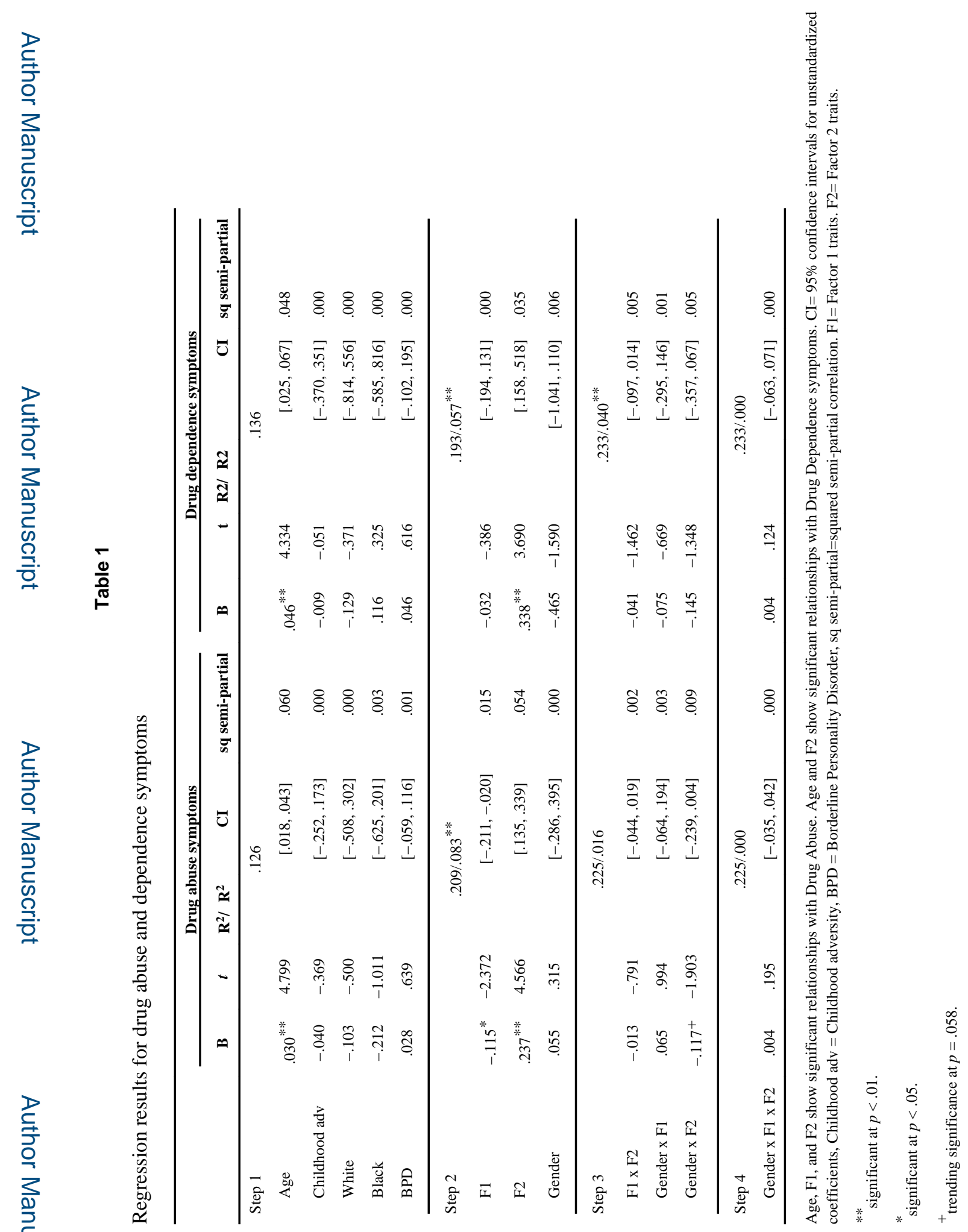


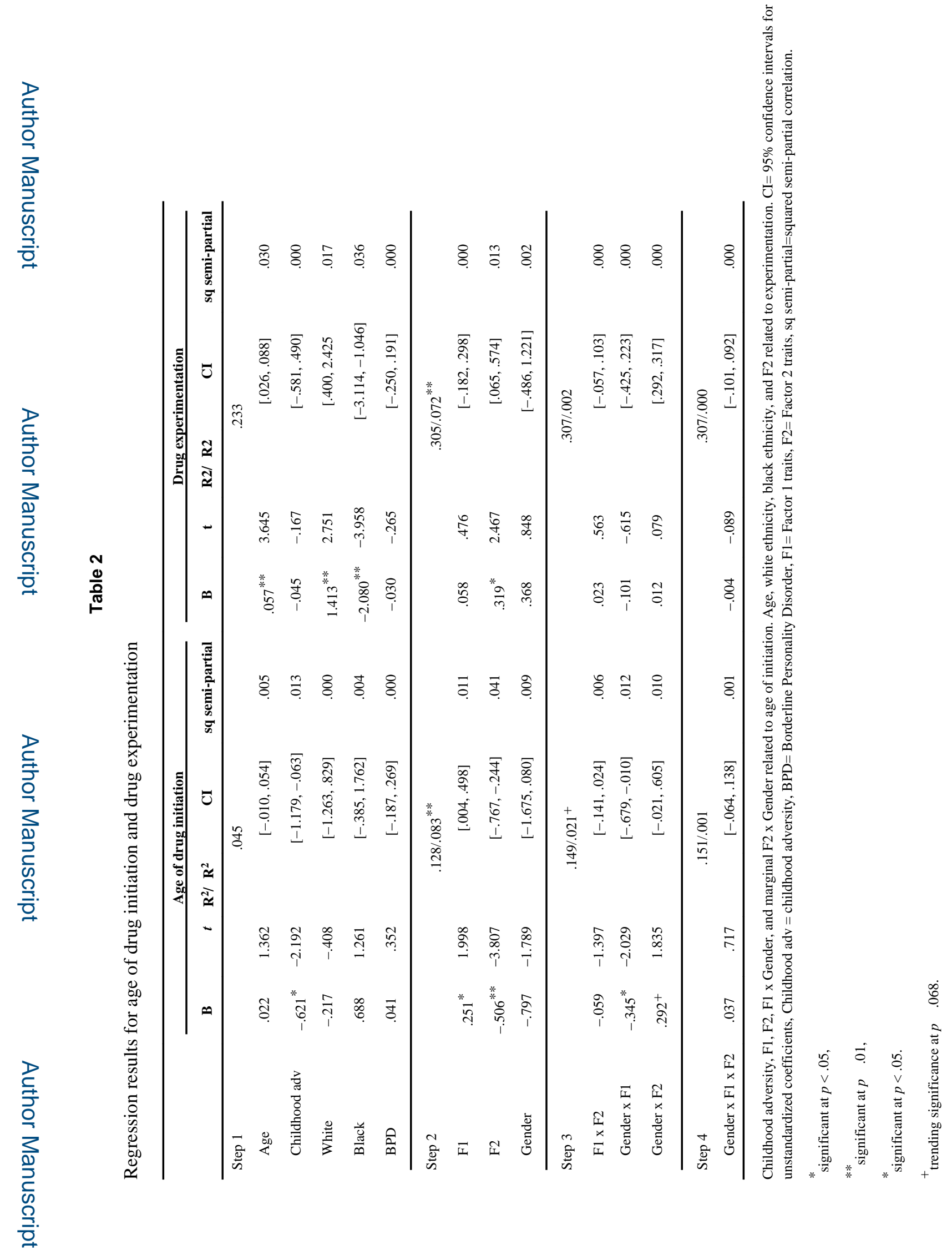



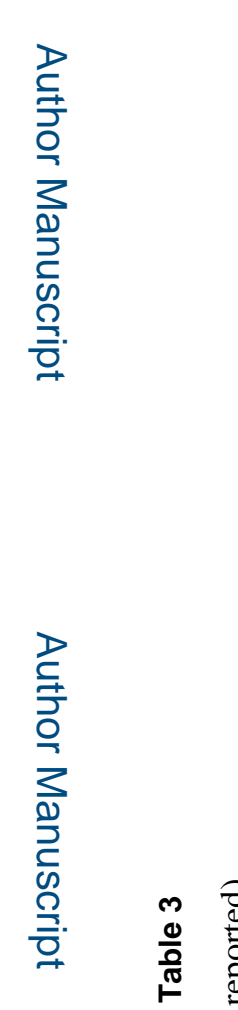

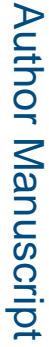

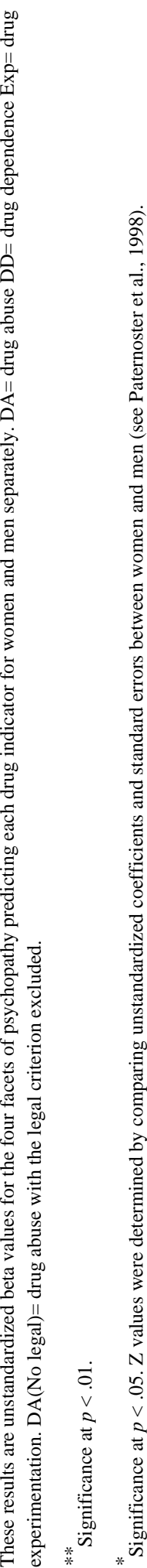

Law Hum Behav. Author manuscript; available in PMC 2016 April 01. 